\section{Resistance of Impatiens Germplasm to Western Flower Thrips Feeding Damage}

\author{
Bejie Herrin $^{1}$ and Daniel Warnock ${ }^{2}$ \\ Department of Natural Resources and Environmental Sciences, University of \\ Illinois, Urbana, IL 61801
}

Additional index words. Impatiens wallerana, Frankliniella occidentalis, plant breeding, host plant resistance

\begin{abstract}
Western flower thrips (WFT) [Frankliniella occidentalis (Pergande)] are an everpresent problem in greenhouse floricultural crops. To determine if host plant resistance varied in impatiens [Impatiens wallerana Hook. f.] nine genotypes were evaluated for resistance to WFT feeding damage. Individual insect-free plants of each genotype were inoculated with $\approx 30$ laboratory-reared WFT. Thrips were allowed to feed on individual plants for a 4-week period during which visual evaluations were conducted every 2 weeks to estimate feeding damage. Feeding damage varied among genotypes and increased with time. At 4 weeks after inoculation, 'Cajun Carmine' and 'Super Elfin Lavender' had significantly less feeding damage than all other genotypes. The San Vito Wild-type germplasm was determined to be highly susceptible to thrips feeding damage based on visual evaluations. Because WFT feeding damage varied among genotypes, the potential for improving impatiens resistance to WFT exists within commercially available germplasm.
\end{abstract}

Western flower thrips (WFT) is a member of the family Thripidae that contains $\approx 1700$ species. Some species of thrips are opportunists, exploiting habitats that are unpredictably favorable (Mound and Teulon, 1995). Such conditions readily exist in commercial greenhouses where breeding may be continuous, resulting in 12 to 15 generations of WFT per year (Lewis, 1997). WFT is the most serious pest of the floricultural industry (Robb et al., 1995) attacking a multitude of crops. Initially restricted to the western United States and Canada, WFT now occurs in commercial greenhouses worldwide (Parrella, 1995; Schreiter et al., 1995).

High-value greenhouse crops such as vegetables, fruit, and especially ornamentals are particularly vulnerable to economic losses associated with thrips feeding damage due to the retail market requirements for an unblemished product (Lewis, 1997). The high capital investment and production costs associated with greenhouse crops increases the potential for high revenue losses due to thrips feeding damage (Lewis, 1997). The impact of thrips infestation in a crop depends on many factors including insect population levels, duration of infestation, environmental influences, plant

Received for publication 25 May 2001. Accepted for publication $10 \mathrm{Feb}$. 2002. This research was supported in part by USDA CRIS Hatch Project ILLU-65-0308. This paper is a portion of a thesis submitted by Bejie Herrin. The authors gratefully acknowledge PanAmerican Seed Co., Express Seed Co., and Sandoz Seeds of Novartis Co. for the donation of impatiens seed.

${ }^{1}$ Graduate Student

${ }^{2}$ Assistant Professor. To whom reprint requests should be addressed. Phone: (217) 244-9380, e-mail: dwarnock@uiuc.edu growth state, and plant vulnerability to direct feeding and oviposition damage or to virus infection (Lewis, 1997). Symptoms of WFT damage include silver mottling or blotching, streaking, and distortion of the leaves and/or petals, all of which reduce the aesthetic quality and marketability of floricultural crops (Parrella and Jones, 1987).

WFT is the most important vector of tospoviruses in many locations of the world (Ullman et al., 1998) and is the only reported vector for impatiens necrotic spot virus (INSV) (Peters etal., 1996), the predominant tospovirus in the U.S. commercial ornamental plant industry (German et al., 1992). Total crop losses due to WFT-related virus damage have occurred in California and North Carolina for chrysanthemum and gloxinia, respectively (Parrella, 1995).

Development of integrated pest management (IPM) programs for ornamentals has lagged behind that in edible crops. Implementation of such programs by commercial floricultural crop growers has been slow because of the low tolerance to pests and damaged plants (Lewis, 1997). Identification and development of plants resistant to thrips will ad- vance existing IPM programs to mitigate WFT damage in floricultural crops.

Resistance in plants can be attributed to antixenosis, antibiosis, or tolerance (Painter, 1951) that impact an insect's host choice, fitness, and population establishment. As cultivars were selected for maximum yield or aesthetic appearance, insect resistance decreased in commercially acceptable cultivars (Broadbent and Allen, 1995). Screening for host-plant resistance and subsequent breeding programs introducing genetic resistance to WFT, while maintaining other desired qualities for yield or appearance, will benefit commercial floricultural crop producers.

Research to incorporate antixenosis, antibiosis, and tolerance properties of plant resistance to WFT into floricultural crops is ongoing (de Jager et al., 1995; van Dijken et al., 1993). However, research related to improving host plant resistance to WFT feeding damage in impatiens has not been published. Pesttolerant plant species or cultivars must be found, the morphological and biochemical characteristics responsible for resistance identified, and these characteristics bred or engineered into commercially acceptable cultivars (Jacobson, 1997).

Evaluation of impatiens germplasm is the first step toward the identification of cultivars with improved levels of resistance to thrips damage. The objective of this study was to identify and confirm the existence of host plant resistance in impatiens genotypes.

\section{Materials and Methods}

Nine impatiens genotypes used for this study (Table 1) were grown in glass-covered greenhouses in Urbana, Ill., beginning Aug. 1999. Seeds of eight genotypes were sown on 24 Aug. 1999 in 609 cell-packs containing Universal Germination Mix (Strong-Lite Corp., Longview, Texas). Seeds were germinated under intermittent mist at temperatures ranging from 21 to $24{ }^{\circ} \mathrm{C}$ and under ambient irradiance. Terminal cuttings taken from stock plants derived from seed of an endemic Costa Rican open-pollinated impatiens population were used to propagate a ninth genotype, the San Vito Wild-type. Cuttings were taken on 6 Sept. 1999, dipped in $0.3 \%$ indolebutyric acid (IBA) rooting powder (Hormex \#3; Brooker Chemical, North Hollywood, Calif.), inserted in Oasis (Smithers-Oasis, Kent, Ohio) rooting blocks, and placed under the previously described greenhouse conditions. Seedlings and cuttings were removed from intermittent mist

Table 1. Cultivar name, propagation method, and seed source for nine impatiens genotypes evaluated for resistance to western flower thrips feeding.

\begin{tabular}{lcc}
\hline \hline Cultivar & Propagation method & Source \\
\hline Cajun Carmine & Seed & Sandoz Seeds \\
Cajun Orange & Seed & Sandoz Seeds \\
Impulse Carmine & Seed & Express Seed Co. \\
Impulse Orange & Seed & Express Seed Co. \\
Impulse Pink & Seed & Express Seed Co. \\
San Vito Wild-type & Cuttings & PanAmerican Seed Co. \\
Stardust Rose & Seed & PanAmerican Seed Co. \\
Super Elfin Lavender & Seed & PanAmerican Seed Co. \\
Super Elfin Scarlet & Seed & PanAmerican Seed Co. \\
\hline
\end{tabular}


on 13 and 20 Sept. 1999, respectively, and placed into a $1.2 \times 1.07 \times 3.35$-m cage covered with $135-\mu \mathrm{m}$ thrips screening made of $55 \mu \mathrm{m}$ smooth poly threads, with a $42 \%$ opening (Greenthumb Group, Downer's Grove, Ill.), to prevent incidental exposure to insect pests found in greenhouses. Plants were fertilized as needed with a water soluble $20 \mathrm{~N}-4.4 \mathrm{P}-16.6 \mathrm{~K}$ (Nutriculture; Plant Marvel Laboratories, Chicago Heights, Ill.) at $300 \mathrm{mg} \cdot \mathrm{L}^{-1} \mathrm{~N}$.

Nine plants of each impatiens genotype were transplanted daily into $12.7-\mathrm{cm}(1.24 \mathrm{~L})$ azalea pots filled with Sunshine Growing Mix (Sun Gro Horticulture, Bellevue, Wash.) between 11 and 14 Oct. 1999 to obtain a total of 324 plants. Plants were placed on greenhouse benches in a randomized complete-block design by transplant date. Immediately after transplanting, each plant was covered with a vented Plexiglas isolation cage $[62 \mathrm{~cm}$ high and $12 \mathrm{~cm}$ diameter with $135-\mu \mathrm{m}$ thrips screening (Greenthumb Group) covering vents] to keep plants free of insects until inoculation with WFT. Pots containing the impatiens genotypes were placed on water collection trays for subirrigation and grown with day/night temperatures set at $24{ }^{\circ} \mathrm{C} / 18{ }^{\circ} \mathrm{C}$, respectively. Commercial production guidelines for impatiens (Corr, 1998) were followed except that no insecticides were applied and the fertilization rate was $300 \mathrm{mg} \cdot \mathrm{L}^{-1} \mathrm{~N}$.

Seven to 10 days after transplanting, plants were inoculated with $\approx 30$ WFT adults and instars from a laboratory colony designed to maintain insect health and feeding aggressiveness (Steiner and Goodwin, 1998). Inoculation began with the first transplanted block on 18 Oct. and ended with the fourth transplanted block on 24 Oct. Thrips were allowed to feed on individual plants for a 4-week period during which visual evaluations to estimate thrips feeding damage were conducted 0,2 , and 4 weeks after inoculation (WAI). Symptoms of WFT damage included leaf silvering or contorted growth due to feeding. The number of leaves exhibiting WFT injury was counted on each plant. Plants were assigned a 1 to 9 rating where a rating of 1 indicated no damaged leaves and a rating of 9 indicated the greatest number of damaged leaves (Table 2). Three researchers independently evaluated each plant. Ratings were pooled and a mean visual rating for each impatiens genotype within each block was calculated. Data were analyzed using Microsoft Excel 2000 spreadsheet software (Microsoft Corp., Redmond, Wash.) and SAS System for Windows, release 6.12 (SAS Institute, Cary, N.C.). To normalize the data and allow appropriate statistical analysis to be conducted, the data were log transformed and analyzed as a randomized complete-block design with sampling (Gomez and Gomez, 1984). This analysis is similar to a standard split-plot design with impatiens genotype as main-plot and weeks after inoculation as sub-plot treatments (Gomez and Gomez, 1984).

\section{Results and Discussion}

Mean feeding damage ratings significantly deviated from normality. The majority of the deviation occurred with the first evaluation (0 WAI). The first evaluation was performed immediately after impatiens plants were inoculated with WFT to provide a minimal baseline to estimate cultivar performance trends during the experiment. As one might expect, the mean visual rating for this date was close to 1.0 , indicating little or no WFT feeding damage. The mean rating for impatiens genotypes increased at 2 and 4 WAI to 2.9 and 4.8 , respectively.

There was a highly significant interaction between impatiens genotype and evaluation date variables (Table 3 ). As exposure time to WFT increased, the corresponding damage ratings increased for all genotypes (Fig. 1). For $0 \mathrm{WAI}$, mean feeding damage ratings were similar for all genotypes (Fig. 1). Mean feeding damage ratings varied among genotypes at 2 and 4 WAI (Fig. 1). Genotypic differences in WFT feeding damage were greatest at 4 WAI. Damage ratings for several genotypes more than doubled between 2 and 4 WAI. Though not quantified, observations indicated that increased damage at 4 WAI was attributable to larger populations of WFT. WFT were observed in large numbers on several genotypes expressing severe damage.

The severity of feeding damage expressed on impatiens increased with time. However, the rate at which feeding damage increased varied among genotypes (Fig. 1). Insect numbers may have contributed to this variation. If a plant is a poor host for an insect, population levels may be reduced compared with a more suitable host plant (Painter, 1951). Insect numbers were not determined in this experiment; however, the interaction between impatiens genotype and evaluation date suggests that some impatiens genotypes negatively impacted WFT populations. Impatiens genotypes with fewer insects may have expressed feeding damage at a slower rate than plants containing larger populations of WFT. Feeding damage displayed at $4 \mathrm{WAI}$ is a meaningful measure of host plant resistance to WFT and is used in the following discussion of individual impatiens genotypes.

At 4 WAI, feeding damage on all genotypes was extensive and rendered plants unmarketable by commercial standards. Plants with damage ratings $<3.0$ were considered commercially acceptable (Table 2). 'Super Elfin Lavender' and 'Cajun Carmine' had the lowest mean damage ratings among impatiens genotypes at 3.7 and 3.4, respectively. These genotypes were not significantly different from one another (Fig. 1). The amount of feeding damage exhibited by these two cultivars increased at a slower rate than all other genotypes (Fig. 1). San Vito Wild-type showed the greatest increase in damage over time among genotypes and may be useful in a host plant resistance breeding program as a susceptible control (Fig. 1). The remaining cultivars were intermediate in the level and rate of increase in WFT feeding damage (Fig. 1).

Within the germplasm examined, the amount of WFT feeding damage expressed and the rate at which feeding damage increased over time varied among impatiens genotypes. Casual observation on insect numbers indicates that some impatiens genotypes negatively impacted WFT populations. This suggests that resistance factors to WFT feeding exist in impatiens germplasm and that resistance to WFT feeding damage may be improved through breeding and selection. 'Cajun Carmine' and 'Super Elfin Lavender' should be included in a host plant resistance breeding program to reduce WFT damage in impatiens. These two cultivars should be integrated into existing IPM programs to reduce insecticide applications to manage WFT during crop production. A reduction in insecticide applications will lower production costs, minimize worker exposure to insecticides, and limit negative environmental impacts.
Table 2. A visual rating scale based on the number of leaves expressing feeding damage that was used to evaluate impatiens cultivar performance when exposed to $\approx 30$ western flower thrips. Ratings between 1 and 3 are considered commercially acceptable while a rating of 4 or greater is considered commercially unacceptable.

\begin{tabular}{lc}
\hline Rating & No. of damaged leaves \\
\hline 1 & 0 \\
2 & 1 to 5 \\
3 & 6 to 10 \\
4 & 11 to 15 \\
5 & 16 to 20 \\
6 & 21 to 25 \\
7 & 26 to 30 \\
8 & 31 to 35 \\
9 & Greater than 35 \\
\hline
\end{tabular}

Table 3. Analysis of variance for western flower thrips feeding damage from four inoculation dates of nine impatiens genotypes. Three researchers independently evaluated nine plants of each cultivar 0,2 , and 4 weeks after inoculating with $\approx 30$ western flower thrips. A mean damage rating was calculated from the scores. Data were log transformed before analysis. Error a was used to test the significance of inoculation date and impatiens genotype. Error b was used to test significance of all other variables (Gomez and Gomez, 1984).

\begin{tabular}{lrrr}
\hline Source & df & F value & $P$ \\
\hline Inoculation date $(\mathrm{I})$ & 3 & 0.28 & NS \\
Impatiens genotype $(\mathrm{G})$ & 8 & 6.08 & $* * *$ \\
$\mathrm{I} \times \mathrm{G}$ (Error a) & 24 & 3.49 & $\mathrm{NS}$ \\
Evaluation date $(\mathrm{E})$ & 2 & 2187.75 & $* * *$ \\
$\mathrm{G} \times \mathrm{E}$ & 16 & 6.87 & $* * *$ \\
$\mathrm{I} \times \mathrm{E}$ & 6 & 2.11 & $\mathrm{NS}$ \\
$\mathrm{I} \times \mathrm{G} \times \mathrm{E}$ (Error b) & 48 & & \\
$\mathrm{Ns}^{*},{ }^{* *},{ }^{* * *}$ Nonsignificant or significant at $P \leq 0.05,0.01$, or 0.001, respectively.
\end{tabular}




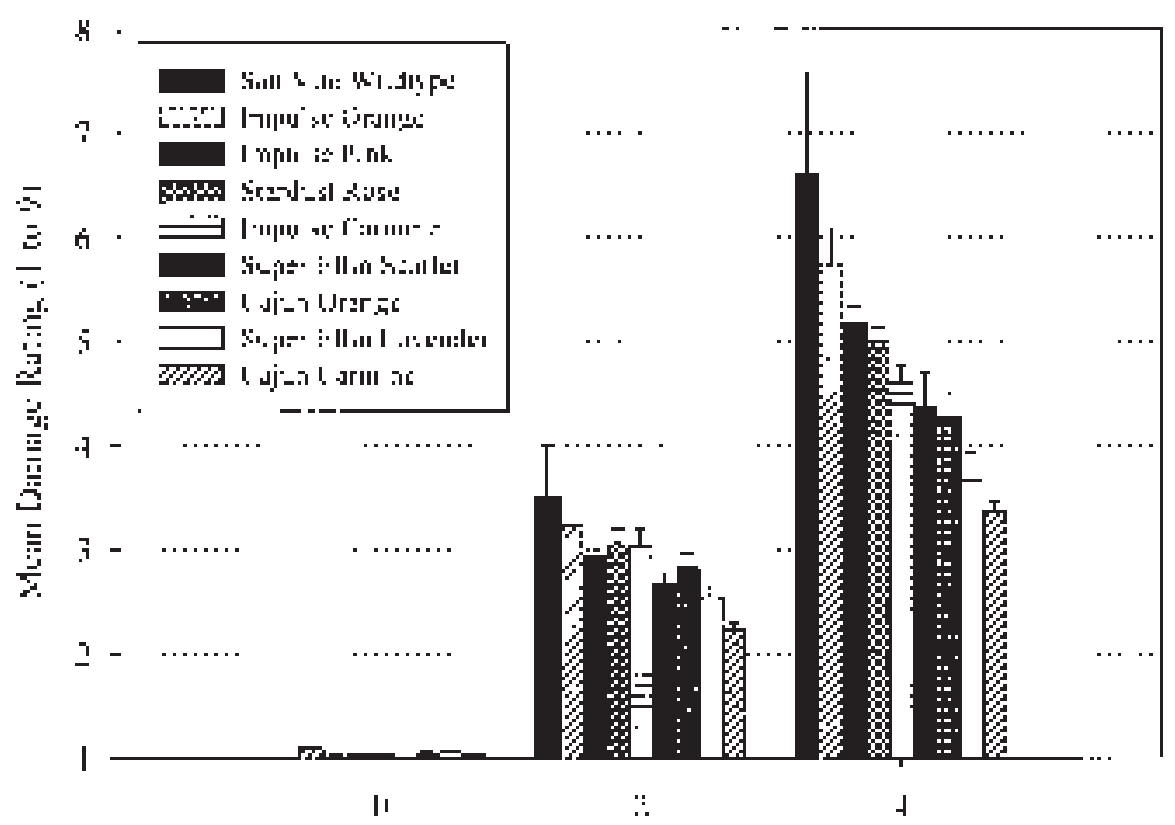

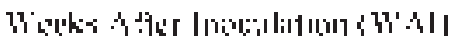

Fig. 1. Changes in mean visual ratings of nine impatiens genotypes after inoculating individual plants with $\approx 30$ western flower thrips. The 1 to 9 visual rating scale is based on the number of plant leaves expressing western flower thrips feeding damage (refer to Table 2). Each mean represents 36 plants of each genotype from four inoculation dates. Three researchers independently evaluated nine plants of each cultivar and a mean damage rating was calculated from the scores. Vertical bars represent a mean $\pm \mathrm{SE}$.

\section{Conclusions}

Varying levels of host plant resistance to WFT feeding exists in impatiens germplasm. When visually evaluating germplasm over time, 'Cajun Carmine' and 'Super Elfin Lavender' exhibited significantly lower WFT feeding damage than seven other genotypes. The San Vito Wild-type had the highest mean damage ratings of any germplasm examined. The detection of variation to WFT feeding damage in this small array of genotypes indicates that enhancing resistance components in impatiens germplasm should be possible through selection. Visually evaluating impatiens germplasm 4 WAI with $\approx 30$ WFT will allow researchers to select potentially resistant germplasm for inclusion in a host plant resistance breeding program. The integration of cultivars with host plant resistance into existing IPM programs designed to limit WFT damage will enhance commercial production of impatiens.

\section{Literature Cited}

Broadbent, A.B. and W.R. Allen. 1995. Interactions within the western flower thrips/tomato spotted wilt virus/host plant complex on virus epidemiology, p. 185-196. In: B.L. Parker, M. Skinner, and T. Lewis (eds.). Thrips biology and management. Plenum Press, New York.

Corr, B. 1998. Impatiens (bedding plants), p. 567575. In: V. Ball (ed.). Ball Redbook, 16th ed. Ball Publishing, Batavia, Ill.

de Jager, C.M., R.P.T. Butot, and A. Guldemond. 1995 Genetic variation in chrysanthemum for resistance to western flower thrips and Thrips tabaci, p. 403-406. In: B.L. Parker, M. Skinner, and T. Lewis (eds.). Thrips biology and management. Plenum Press, New York.

German, T.L., D.E. Ullman, and J.W. Moyer. 1992. Tospoviruses: diagnosis, molecular biology, phylogeny, and vector relationships. Ann. Rev. of Phytopathol. 30:315-348.

Gomez, K.A. and A.A. Gomez. 1984. Statistical procedures for agricultural research. 2nd ed. Wiley, New York.

Jacobson, R.J. 1997. Integrated pest management (IPM) in glasshouses, p. 639-657. In: T. Lewis (ed.). Thrips as crop pests. CAB Intl., New York.

Lewis, T. 1997. Pest thrips in perspective, p. 1-15, 650. In: T. Lewis (ed.). Thrips as crop pests. CAB Intl., New York.

Mound, L.A. and D.A.J. Teulon. 1995 Thysanoptera as phytophagous opportunists, p. 3-21. In: B.L. Parker, M. Skinner, and T. Lewis (eds.). Thrips biology and management. Plenum Press, New York.

Painter, R.H. 1951. Insect resistance in crop plants. Macmillan, New York.

Parrella, M.P. 1995. IPM-Approaches and prospects, p. 357-363. In: B.L. Parker, M. Skinner, and T. Lewis (eds.). Thrips biology and management. Plenum Press, New York.

Parrella, M.P. and V.P. Jones. 1987. Development of integrated pest management strategies in floricultural crops. Bul. Entomol. Soc. Amer. 33:28-34.

Peters, D., I. Wijkamp, F. van de Wetering, and R. Goldbach. 1996. Vector relations in the transmission and epidemiology of tospoviruses. Acta Hort. 431:29-43.

Robb, K.L., J. Newman, J.K. Virzi, and M.P. Parrella. 1995. Insecticide resistance in western flower thrips, p. 341-346. In: B.L. Parker, M. Skinner, and T. Lewis (eds.). Thrips biology and management. Plenum Press, New York.

Schreiter, Gerd, T.M. Butt, A. Beckett, and G. Moritz. 1995. Electron microscope studies of infection by Verticillium lecanii (Zimm.) Viégas of western flower thrips, p. 297-304. In: B.L. Parker, M. Skinner, and T. Lewis (eds.). Thrips biology and management. Plenum Press, New York.

Steiner, M.Y. and S. Goodwin. 1998. Methods for collecting and rearing thrips (Thysanoptera) and their natural enemies. Austral. J. Entomol. 37:101-106.

Ullman, D.E., C.A. Casey, A.E. Whitfield, L.R. Campbell, K.L. Robb, R.B. Medeiros, T.L. German, and J.L. Sherwood. 1998. Thrips and tospoviruses: Present and future strategies for management. Proc. Intl. Conf., Brighton, U.K., 16-19 Nov. 1998. Brighton Crop Protection Conf.: Pests \& disease-1998. 2:391-400.

van Dijken, F.R., G. Breugem, M.T.A. Dik, B. Gebala, C. Soria, and J. de Jong. 1993. Effects of flower colour of chrysanthemum on host plant resistance to the western flower thrips (Frankliniella occidentals Pergande) in nochoice situations. Proc. Expt. Appl. Entomol. N.E.V. Amsterdam 4:45-46. 